\title{
Sustentabilidade, Planejamento Urbano e Instrumentos de Gestão do Patrimônio e da Paisagem Cultural em Bento Gonçalves/RS
}

\author{
BERTOCO, Cristiane ${ }^{1}$ \\ MEDEIROS, Ana Elisabete ${ }^{2}$
}

\author{
${ }^{1}$ Curso de Especialização em Reabilitação Ambiental Sustentável Arquitetônica e Urbanística, \\ Universidade de Brasília, Brasília, Brasil. crisbertoco.arq@gmail.com \\ ${ }^{2}$ Universidade de Brasília, Brasília, Brasil. ana@unb.br
}

\section{Resumo}

Buscando instrumentos mais sustentáveis de preservação do patrimônio cultural, o trabalho se propõe a pesquisar como se dá a relação entre os instrumentos de gestão preservacionistas e aqueles voltados ao planejamento urbano municipal, utilizando como metodologias revisão bibliográfica e estudo de caso. Busca uma discussão teórica sobre patrimônio cultural e desenvolvimento sustentável, valorização e reabilitação através do turismo e indicações geográficas, gestão e planejamento urbano através do Plano Diretor. Como estudo de caso, adota-se o município de Bento Gonçalves, no Rio Grande do Sul, polo turístico e vitivinícola, abordado sob dois pontos de vista: a valorização do patrimônio através de roteiros turísticos e indicações geográficas, e a gestão e planejamento urbano na preservação dos bens edificados e da paisagem urbana e rural. $O$ estudo resulta na reflexão dos desafios na construção de um pacto de gestão da paisagem cultural através do Plano Diretor e dos Conselhos Municipais.

Palavras-Chave: Patrimônio cultural, turismo, planejamento urbano, desenvolvimento sustentável.

\begin{abstract}
Seeking more sustainable instruments of cultural heritage preservation, the study aims to investigate how is the relationship between preservationists management tools and those focused on municipal urban planning, using methodologies such as literature review and case study. Search a theoretical discussion of cultural heritage and sustainable development, recovery and rehabilitation through tourism and geographical indications, management and urban planning through the Master Plan. As a case study, we adopt the municipality of Bento Gonçalves, in Rio Grande do Sul, tourist pole and wine, approached from two points of view: the recovery of itinerary tours and geographical indications, and the management and urban planning in preserving of real estate and strengthen the urban and rural landscape. The study results in the reflection of the challenges in building a pact management of the cultural landscape through the Master Plan and Municipal Councils.
\end{abstract}

Key-Words: Cultural heritage, tourism, urban planning, sustainable development. 


\section{Introdução}

Desde as primeiras definições de patrimônio até a definição adotada pela Constituição Brasileira, em 1988, a abordagem sobre patrimônio cultural tem se ampliado. Observa-se, no entanto, que os instrumentos tradicionais de preservação nem sempre dão conta de um patrimônio que vem se renovando cada vez mais rápido, especialmente na dimensão local. Assim, a maioria dos municípios brasileiros ainda não possui a chancela de órgão nacional, estadual ou mesmo municipal de preservação.

O uso de instrumentos de preservação pode apresentar-se frágil quando dependente apenas da gestão municipal para a salvaguarda, tornando as cidades-patrimônio expostas à especulação imobiliária, decisões políticas, pressão por densificação e expansão urbana ou interesses privados. Em muitos casos, a urbanização desordenada ainda põe manifestações materiais ou imateriais em risco.

O uso turístico, normalmente fonte de reabilitação e sustentabilidade econômica desses bens, quando perdidos esses valores, perde apelo, sendo inviabilizado. A perda de referência e desvalorização das atividades tradicionais locais também expulsa populações, expondo-as à degradação social e desemprego.

Instrumentos para a prática preservacionista são apontados pelo Estatuto da Cidade e pela Constituição Federal Brasileira, na forma de incentivos fiscais, inventários, vigilância, constituição de conselhos, entre outros. $O$ instrumento tradicionalmente aplicado e mais conhecido no Brasil é o tombamento, mas não é o único, além de nem sempre ser o mais adequado para a preservação efetiva.

A instituição do tombamento é vista pela sociedade de forma negativa, pois o papel do poder público tem sido impor restrições, o que acaba desvalorizando o imóvel pela sociedade, resultando no seu abandono e degradação. O guia para a elaboração de Planos Diretores Participativos sugere como solução a integração do planejamento macro, representado pelo Plano Diretor, e o planejamento estratégico, tratando-se a cidade como um todo e utilizando os inventários culturais como instrumentos de análise urbana (BRASIL, 2004).
Buscando responder como se dá a relação entre os instrumentos de gestão preservacionistas e aqueles voltados ao planejamento urbano municipal, adotam-se as metodologias de revisão bibliográfica e estudo de caso. Busca-se primeiramente a discussão teórica relativa ao patrimônio cultural, desenvolvimento sustentável e paisagem cultural, às formas de valorização, sustentação econômica e reabilitação social, como o turismo cultural e as indicações geográficas, bem como ao planejamento e gestão urbana e seu papel na preservação do patrimônio edificado e da paisagem cultural.

Para o entendimento desta realidade, adota-se o Município de Bento Gonçalves, na Serra Gaúcha, como estudo de caso, buscando entender as aplicações dos instrumentos de planejamento e gestão para a preservação do patrimônio cultural em suas diversas expressões. Como uma cidade em expansão, com pouco mais de cem mil habitantes, sofre com todas as dificuldades de um município desse porte, exemplificando as contradições existentes na maioria dos municípios brasileiros cujo reconhecimento cultural está iniciando.

O estudo de caso contextualiza historicamente o processo de formação da região e do município, avalia os principais roteiros turísticos e indicações geográficas, sua importância na valorização do patrimônio cultural local, bem como estuda os instrumentos de preservação, planejamento e gestão em Bento Gonçalves.

A pesquisa busca o reconhecimento das políticas de preservação do patrimônio cultural, bem como dos instrumentos de gestão e planejamento urbano para o desenvolvimento sustentável, servindo de subsídio especialmente no momento em que diversos municípios se mobilizam para a revisão de seus Planos Diretores e Inventários Culturais.

\section{Planejamento, patrimônio cultural e desenvolvimento sustentável}

O planejamento das cidades-patrimônio é um tema complexo, em que os mais diversos atores sociais possuem opiniões divergentes. "O tecido urbano é um conjunto de exemplares de arquiteturas maiores e menores que, ao longo do tempo, vão se substituindo umas às outras, refletindo, fisicamente, as transformações da sociedade que o cria e o vivencia, segundo suas necessidades e crenças e conflitos" (MEDEIROS, 2002, p. 47). O desafio é 
planejar a próxima camada combinando os diversos interesses sem ignorar o que já foi feito (HARVEY, 1992, apud GOMES, 2011).

No debate do que, onde e como merece ser reconhecido e preservado como patrimônio, surge a reflexão de como conciliar, planejar e gerir a preservação e o desenvolvimento, garantindo o processo democrático.

\subsection{Patrimônio cultural e desenvolvimento sustentável}

A partir dos anos 1960, ao conceito de patrimônio cultural são integrados "novas formas, novos valores, nova expansão do quadro cronológico [...] aos valores já existentes vêm somar-se o 'valor de uso' e o 'valor econômico', ou seja, o atendimento do 'patrimônio cultural' como vetor de desenvolvimento" (MEDEIROS, 2002, p. 50).

Com o manifesto de Amsterdã (CONSELHO DA EUROPA, 1975), a conservação integrada do patrimônio arquitetônico surge como pressuposto do planejamento urbano e regional, realizada através de um espírito de justiça social, integrando-os à vida dos cidadãos, no planejamento físico-territorial e nos planos urbanos, considerando tanto seu valor educativo quanto econômico.

Por sua vez, o relatório 'Nossa Diversidade Criadora' (CUÉLLAR, 1996) integra o patrimônio cultural como instrumento para o desenvolvimento sustentável, revalorizando as relações entre cultura e meio ambiente. A concepção de desenvolvimento como um caminho único, uniforme e linear, trazia consigo a tendência de eliminar a diversidade cultural da humanidade, limitando sua capacidade criativa e logo, a sustentabilidade de suas ações.

A Recomendação Europa sobre a Conservação Integrada das áreas de Paisagens Culturais como integrante das políticas paisagísticas vem integrar os conceitos, em busca do "equilíbrio harmonioso de relações entre a sociedade e seu meio ambiente, com vistas à promoção do desenvolvimento econômico sustentável" (CONSELHO DA EUROPA, 1995, p.2).

\subsection{Turismo e indicações geográficas na valorização do patrimônio cultural}

Há muitas manifestações no sentido de valorizar economicamente e socialmente o Patrimônio Cultural, através de mecanismos de intervenção preservacionista estimulando a sua exploração turística como forma de desenvolvimento. As Normas de Quito debatem a necessidade de conservação e utilização do patrimônio cultural na demanda por medidas urgentes de conservação, ao mesmo tempo da necessidade de potencializar o desenvolvimento local, reconhecendo-se os bens do patrimônio cultural como recursos econômicos, sugerindo o uso turístico como mais adequado (OEA, 1967).

No âmbito da competitividade urbana e do planejamento estratégico, o patrimônio cultural assume o status de mercadoria e "moeda de valor", sendo a venda da imagem da cidade uma estratégia de marketing para o incremento econômico e o desenvolvimento local. A cultura e o patrimônio, sob essa ótica, se tornam preciosas mercadorias, que ressaltam a particularidade do lugar (GOMES, 2011). Por outro lado, o turismo pode trazer o processo de gentrificação, entendido como "uma segregação espacial não pela renda, mas pela estetização da vida cotidiana" (GOMES, 2011, p. 25).

O turismo cultural, que utiliza o patrimônio cultural como recurso econômico abrange atividades de vivência de elementos do patrimônio cultural e eventos culturais. Quando organizado, planejado e promovido dentro de uma identidade, na forma de itinerário, é definido Roteiro Turístico (BERTOCO, 2008)

Dentro desse contexto, o ICOMOS - International Council on Monuments and Sites - através da Carta dos Itinerários Culturais, em 2008, reconhece as vias de comunicação como uma nova categoria de patrimônio cultural. "O itinerário cultural representa processos evolutivos, interativos e dinâmicos das relações interculturais humanas e destaca a rica diversidade das contribuições dos povos para o patrimônio cultural” (DELPHIM, 2013, p. 28).

Já as indicações geográficas são definidas na valorização de um produto relacionado à identidade de um território, integrando no reconhecimento da qualidade de um produto os conceitos de territórios e itinerários culturais. São embasadas em estudos de caracterização geográfica do território que se pretende reconhecer, mediante estudos do contexto histórico, socioeconômico e ambiental, entre outros, de forma a caracterizar sua paisagem (FALCADE e MANDELLI, 1999). 
Esses conceitos inter-relacionados ilustram a complexidade do tema, que em suas diversas expressões, vistas de forma integrada, vêm de encontro ao conceito de Paisagem Cultural.

\subsection{Instrumentos de preservação, planejamento e gestão urbana}

Com a Constituição Federal de 1998, o Plano Diretor visto como um processo político, em etapas sucessivas, com a participação efetiva da população, passa a ser definido como "um conjunto de princípios e regras orientadoras da ação dos agentes que constroem e utilizam o espaço urbano" (BRASIL, 2002, p. 40), devendo partir da leitura da cidade real, instrumentalizando e embasando a gestão pactuada da cidade.

Para além dos instrumentos jurídicos mais conhecidos, como tombamento e inventários, Araújo (2009) indica a possibilidade de pensar as áreas de conservação no Brasil através do estabelecimento de Áreas de Diretrizes Especiais, estabelecidas através do Plano Diretor, delimitando perímetros e parâmetros urbanísticos, fiscais e de atividades, segundo as peculiaridades do sítio, sobrepondo-se ao zoneamento.

Por sua vez, a chancela, instrumento utilizado pelo IPHAN para a preservação da paisagem cultural, precede de um plano e um pacto de gestão, envolvendo o poder público, a sociedade civil e a iniciativa privada, através da gestão compartilhada do território protegido. O pacto deve definir o plano de atuação a curto, médio e longo prazo, considerando o caráter dinâmico da cultura e das ações humanas sobre o território (IPHAN, 2011). Sendo assim, "o próprio Plano Diretor pode ser entendido como pacto [...] desde que contemple as medidas necessárias à preservação da paisagem cultural que se deseja chancelar" (IPHAN, 2011, p. 4).

Portanto, a sustentabilidade das ações de preservação do patrimônio cultural depende da integração dos instrumentos de planejamento, gestão e preservação, podendo ser adotados como pacto de gestão o próprio Plano Diretor do Município, assim como os acordos firmados entre os envolvidos na formatação de roteiros turísticos e culturais e indicações geográficas de produtos que dependem da preservação da cultura, da paisagem e do território.

\section{Valorização do Patrimônio Cultural através do turismo em Bento Gonçalves/RS}

O município de Bento Gonçalves, localiza-se na região sul do Brasil, na encosta superior do nordeste do Rio Grande do Sul, a 124 quilômetros de Porto Alegre, na Região Metropolitana da Serra Gaúcha. A maior parte do território do município possui ocupação rural, dividida entre os distritos de São Pedro, Vale dos Vinhedos, Faria Lemos e Tuiuty, além da sede definida pelo perímetro urbano.

Sendo um dos berços da colonização italiana no Rio Grande do Sul, Bento Gonçalves tem atualmente grande projeção como um dos 65 pólos indutores do turismo no Brasil. A indústria de móveis é a principal força econômica, no entanto a indústria vinícola e a vitivinicultura também possuem grande projeção, sendo a cidade conhecida como capital brasileira da uva e do vinho, integrando em seu território a primeira região com Brasil contemplada com Indicação Geográfica para vinhos, nas modalidades Indicação de Procedência e Denominação de Origem (DELPHIM, 2013).

A história da ocupação do território e do desenvolvimento econômico local, no entanto, não se deu de forma fácil. $O$ fato de hoje ser privilegiada com alto desenvolvimento econômico está profundamente ligado ao processo histórico e ao empreendedorismo dos imigrantes, necessário à sua sobrevivência. Na realidade, a cultura e as construções relacionadas à imigração eram menosprezadas pela população local.

Conforme Delphim (2013), os colonos foram submetidos a diversas arbitrariedades ao longo do processo de imigração, desde a partida da Itália, com a promessa de uma terra fértil comparada a uma nova Canaã, à viagem submetendo-os à fome, doenças e perigos do mar até a chegada a uma floresta de topografia difícil, com animais selvagens, vegetação e alimentos desconhecidos. De Paris (2006) esclarece ainda que a partir da década de 1930 os descendentes de italianos foram proibidos de falar seu dialeto, culminando na vergonha e negação de sua cultura e de suas construções.

\subsection{Projeto Cultural Caminhos de Pedra}

A valorização da cultura da imigração italiana se iniciou apenas nos anos 1990, com o Projeto Cultural Caminhos de Pedra, através da iniciativa 
de valorização por meio de um projeto de resgate cultural. Esse modelo promoveu a reabilitação ambiental, desenvolvimento econômico e humano da comunidade rural do Distrito de São Pedro, por meio de um roteiro turístico. Segundo Posenato (1998), sua preocupação inicial era preservar e valorizar as antigas edificações, que representavam para a população, naquele momento, a vergonha de sentirem-se brasileiros de segunda categoria.

Outro problema era o custo de sua manutenção, tornando "necessário encontrar uma forma em que a conservação da herança cultural proporcionasse renda aos usuários [...] Sendo impraticável a valorização a partir da comunidade usuária, devia ser buscado no público externo o agente valorizador" (POSENATO, 1998, p. 4). Para o autor, o tombamento compulsório não é um instrumento sustentável, uma vez que não dá ao proprietário instrumentos para a manutenção do imóvel. Sendo assim, o uso social e valorização do local pelo uso turístico é que permitiu a valorização cultural em longo prazo, devolvendo à comunidade a possibilidade de uma vida digna (POSENATO, 1998).

O projeto prevê uma ampla gama de empreendimentos artesanais historicamente relevantes na formação do município e que ao longo do tempo desenvolveram a indústria na região. Esses locais deveriam representar como era o funcionamento de cada atividade nas diversas épocas, oferecendo a venda dos produtos artesanais ao turista e à população urbana, sem, no entanto, encenar o passado, de forma que as pessoas realmente vivem no local onde suas famílias se desenvolveram e tiram dali o seu sustento (POSENATO, 1998).

Hoje "a sustentabilidade econômica do projeto é proveniente principalmente do turismo [...] o projeto é a segunda fonte de renda das famílias locais" (OLTRAMARI E BORGUETTI, 2005, p. 34). Além de fontes de recursos na esfera municipal, estadual e federal, foi criado o Fundo Rotativo Caminhos de Pedra, onde o valor recaptado pela associação é novamente investido, gerando um círculo econômico através de empréstimos programados.

\subsection{O Vale dos Vinhedos}

Outra iniciativa que se desenvolveu a partir dos anos noventa foi o turismo vitivinícola ou enoturismo, no Vale dos Vinhedos, que tomou projeção internacional quando da obtenção da primeira indicação geográfica de procedência para vinhos no Brasil, em 2002 e denominação de origem em 2012. (APROVALE, 2012).

Com a participação inicial de seis vinícolas, tinha como motivações iniciais a melhoria na qualidade dos vinhos, a agregação de valor aos produtos, a divulgação da região através do estímulo ao turismo e ao crescimento cultural da comunidade, a geração de empregos, mantendo o agricultor no meio rural e a valorização do patrimônio dos agricultores e das empresas. O perfil dos associados é variado, havendo vinícolas familiares com elaboração limitada e venda exclusiva em seu varejo - que corresponde muitas vezes à casa antiga da família - mas também grandes empresas com presença internacional, que se desenvolveram ao longo dos anos. Assim, foram definidas regras que determinam a identidade do produto, como variedades de uvas utilizadas, quantidade máxima a ser produzida e forma que devem ser processadas. (APROVALE, 2012).

Para Flores e Flores (2012) o Vale dos Vinhedos possui como principais características o patrimônio cultural representado pelos costumes, tradições e hábitos, onde a sustentação da videira é feita por Plátanos, desenhando uma paisagem espetacular, formada por cadeias de montanhas cobertas de mata nativa e vinhedos. No entanto, as autoras apontam como condição preocupante a possível descaracterização dessas paisagens em função da alteração do sistema de plantio das videiras, abandonando-se os sistemas tradicionais pelos sistemas europeus de plantio e colheita, bem como pela proliferação de condomínios, loteamentos e áreas de invasão, em desacordo com as diretrizes da Indicação Geográfica.

Ainda assim a valorização da cultura do imigrante trouxe uma consciência do valor da paisagem e do patrimônio edificado que anteriormente praticamente não existia. As famílias que ainda possuíam edificações antigas passaram a preserválas, ao invés de substituí-las, utilizando os porões e construções anteriormente em desuso, no processo produtivo ou no atendimento ao turista.

\subsection{Outros itinerários culturais e a consolidação do patrimônio cultural como recurso turístico}

Atualmente, a Serra Gaúcha possui quatro das cinco indicações geográficas no Brasil para 
vinhos. Todas as indicações oferecem visitação sob o modelo de roteiros turísticos. Em Bento Gonçalves, são oferecidos sete roteiros turísticos, todos relacionados ao patrimônio cultural e natural: Caminhos de Pedra, Vale dos Vinhedos, Vale do Rio das Antas, Rota das Cantinas Históricas, Encantos da Eulália, Bento City Tour e o Passeio de Maria Fumaça, resultando na maior parte do território dividida em roteiros turísticos (figura 1).

Figura 1: Roteiros turísticos, itinerários culturais e atrativos em Bento Gonçalves e região. (a) Casarão Toniolo - Encantos da Eulália; (b) Vinícola Barcarola Vale dos Vinhedos; (c) Pousada Cantelli - Caminhos de Pedra.
Assim, o turismo tornou-se a principal fonte de valorização do patrimônio cultural no município, em suas dimensões tangíveis e intangíveis. Em uma região em que o fator econômico faz parte da cultura, as edificações antigas, paisagens notáveis, os produtos coloniais e até mesmo a própria linguagem, somente foram valorizadas ao tomarem um valor econômico, tornando-se produtos turísticos. Ao mesmo tempo, fortaleceu-se a agroindústria e se criaram empreendimentos familiares, ajudando a manter a população no meio rural.

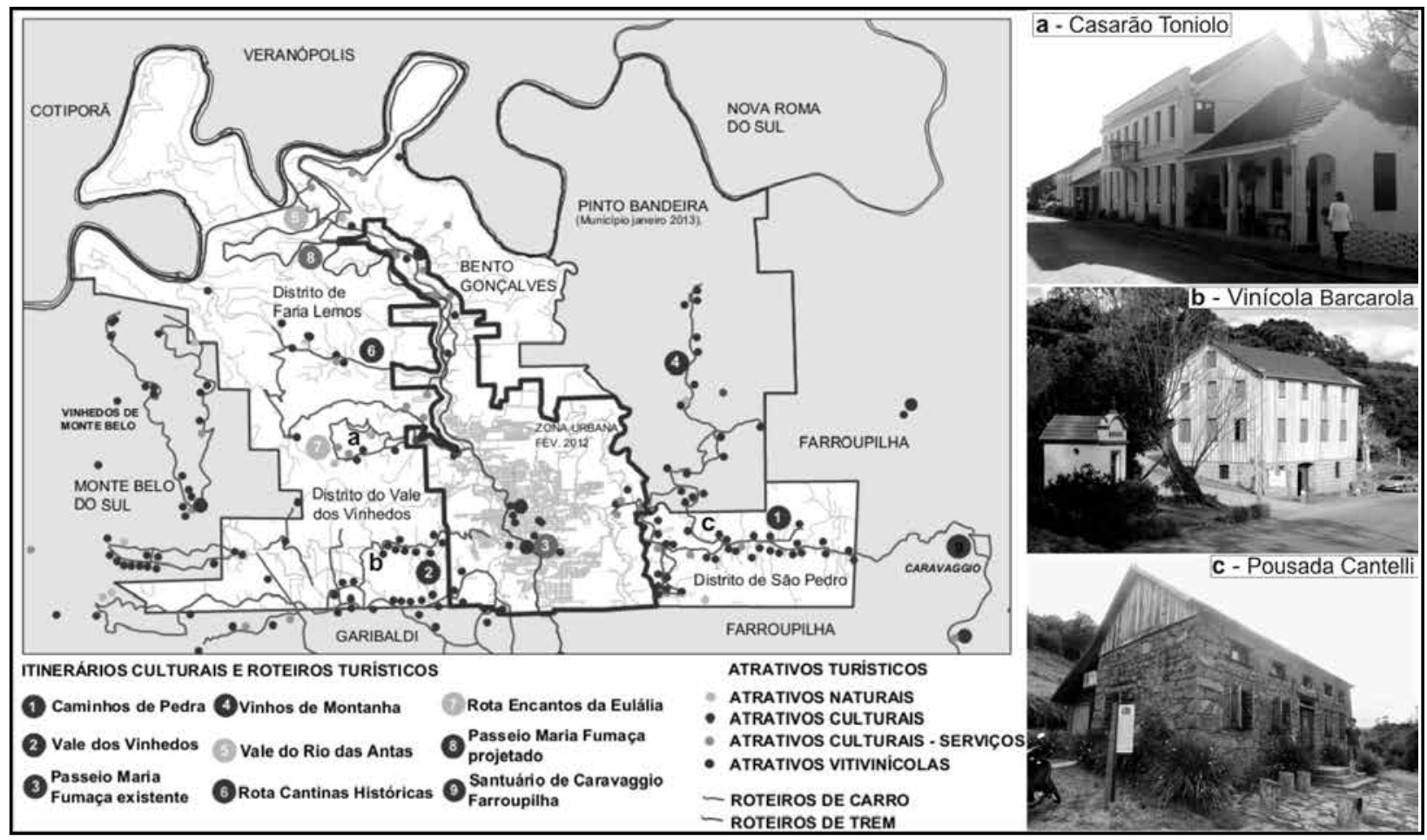

Fonte: adaptado pela autora de Bertoco (2008) e Bento Gonçalves (2006); imagens de Cristiane Bertoco (2014).

Os produtos culturais oferecidos são diversos, todos envolvidos com a cultura da imigração, abrangendo o ecoturismo, turismo cultural, de aventura, rural e enoturismo. O patrimônio imaterial também é valorizado através da promoção de eventos, como a festa do vinho colonial e a festa da vindima colheita da uva, onde a culinária, a colheita e pisa da uva, as músicas tradicionais e cantorias, os jogos tradicionais e o tipo humano, são apresentados à comunidade local e aos turistas, incentivando sua preservação.

\section{Instrumentos e estratégias de preservação, planejamento e gestão urbana em Bento Gonçalves/ RS}

Os órgãos responsáveis pela gestão da preservação do patrimônio edificado, no município, são o Instituto de Pesquisa e Planejamento Urbano - IPURB órgão executivo vinculado à Prefeitura Municipal, e o Conselho Municipal do Patrimônio Histórico e Cultural de Bento Gonçalves - COMPAHC - com poder deliberativo e vinculado ao IPURB. 
Assim como a maioria das cidades, a preservação de bens culturais iniciou-se através do tombamento dos bens considerados de excepcional valor histórico e artístico na memória do município. Os bens tombados seguem a concepção tradicional de reconhecimento de arquiteturas monumentais, de uso institucional, religioso ou de excepcional valor artístico, na maioria edifícios públicos ou religiosos. A falta de documentação acaba por tornar o instrumento ineficaz na efetiva preservação do bem, uma vez que não há cadastro dos elementos a serem preservados.

Já o Inventário do Patrimônio Cultural do Rio Grande do Sul, elaborado entre 1994 e 1996, reconhece como patrimônio cultural aproximadamente quatrocentos bens edificados em Bento Gonçalves. Os bens cadastrados pelo inventário envolvem diversas expressões do patrimônio edificado, incluindo arquitetura vernacular, industrial e agrícola. Embora destes quatrocentos bens apenas nove tenham sido tombados pelo município, os bens inventariados, juntamente com os bens com mais de vinte anos com potencial de integrar o patrimônio cultural são protegidos pelo Plano Diretor Municipal de Desenvolvimento Integrado - PDDI, dependendo de análise do COMPAHC para qualquer intervenção (BENTO GONÇALVES, 2006).

\subsection{Plano Diretor Municipal e as zonas de preservação da paisagem}

O atual Plano Diretor do Município de Bento Gonçalves é regido pela Lei Complementar $n^{\circ}$ 103 , de 26 de outubro de 2006, que dispõe sobre o desenvolvimento urbano e rural do município de Bento Gonçalves, institui o novo Plano Diretor de Desenvolvimento Integrado do Município de Bento Gonçalves e dá outras providências (BENTO GONÇALVES, 2006).

Construído em conjunto com a comunidade, adequou a legislação existente aos instrumentos criados pelo Estatuto da Cidade, criando espaços de participação contínua da sociedade na gestão do Plano Diretor, através de Conselhos Municipais de planejamento urbano, planejamento distrital, patrimônio cultural e Fórum de Políticas Públicas, organizados em um Sistema de Planejamento e Gestão.

O principal instrumento do PDDI na preservação do patrimônio cultural é a inclusão, no zoneamento de uso do solo urbano e rural - de zonas de preservação ao patrimônio histórico e cultural e zonas de preservação à paisagem. Do ponto de vista da preservação do patrimônio cultural e da paisagem na zona urbana, destacam-se três zonas.

A Zona de Preservação ao Patrimônio Histórico e Cultural corresponde a duas áreas especiais de preservação conhecidas como Cidade Baixa e Cidade Alta, sendo a sua delimitação correspondente a edificações integrantes do Inventário do Patrimônio Cultural que integram esses dois conjuntos. A preservação do patrimônio edificado é incentivada através de instrumentos do Estatuto da Cidade, sob a gestão do IPURB e do COMPAHC. Embora sua delimitação seja insuficiente dado o grande número de edificações inventariadas e, portanto, frágil em sua efetiva proteção, remete ao Inventário do Patrimônio Histórico e Cultural como um todo e prevê que as edificações que ainda não integrem o Inventário possam ser mesmo assim beneficiadas, estando sua gestão sujeita à deliberação do COMPAHC.

A Zona Comercial Central, por sua vez, caracterizase como o entorno das edificações integrantes da Zona de Preservação ao Patrimônio Histórico e Cultural, onde a densificação seria controlada de forma a permitir a preservação da paisagem urbana. No entanto, observa-se que altos índices de aproveitamento e altura permitidos na zona acabam por estimular a especulação imobiliária.

Já a ZPPVV - Zona de Preservação à Paisagem do Vale dos Vinhedos Urbana propõe-se a ordenar, de forma sustentável, áreas destinadas à viticultura do território da Indicação Geográfica de Vinhos do Vale dos Vinhedos, mas que integram o perímetro urbano do município. O uso e ocupação do solo são controlados de forma que os lotes e índices construtivos são menores em relação às demais zonas urbanas. É incentivada a vitivinicultura, protegendo os vinhedos de forma que as áreas de cultivo somente possam ser substituídas por novas áreas dentro da mesma propriedade, bem como protegendo a linha do horizonte de forma que nenhuma edificação pode seccioná-la. Por outro lado, a dificuldade de fiscalização quanto à substituição dos vinhedos, bem como o processo de gentrificação causado pela venda das propriedades, aliado à busca pela paisagem bucólica e tranqüila, tem gerado grande especulação imobiliária que pode trazer, com o tempo, a urbanização excessiva e conseqüente descaracterização dessa paisagem. 
O zoneamento rural, por sua vez, define diretrizes de ocupação do espaço rural segundo as características e vocações de cada Distrito, com foco na preservação da paisagem rural e atividades culturais particulares de cada núcleo. São previstas áreas de controle especial ou de conservação, como áreas de preservação ambiental, de proteção paisagística e do patrimônio histórico e cultural, através de um modelo espacial básico ou de exceções por padrão emergente. Toda nova atividade é sujeita a avaliação pelo IPURB através de Estudo de Impacto de Inovações, tendo sua aprovação final através do Conselho Distrital de Planejamento correspondente ao distrito.

Entre as diretrizes estabelecidas, os distritos do Vale dos Vinhedos e de São Pedro são os que possuem normas específicas de preservação delimitadas para o Distrito como um todo. O Distrito do Vale dos Vinhedos destaca-se pela 'Área de Proteção a Paisagem Vale dos Vinhedos', tendo como elementos protegidos os parreirais e a linha do horizonte, da mesma forma que a ZPPVV, diferenciando-se da mesma pela submissão ao conselho distrital.

O Distrito de São Pedro define normas de proteção para a 'Área de Proteção Paisagística, Ambiental e do Patrimônio Histórico e Cultural', tendo por elementos protegidos os sítios históricos, de interesse turístico e a paisagem natural. Através das condições de proteção definidas para essa área declara de preservação a paisagem, as edificações, sítios históricos e de interesse turístico. São definidos como instrumentos de proteção e diretrizes de intervenção o Inventário e Projeto Cultural Caminhos de Pedra, bem como a submissão de todos os projetos de edificações, propostas de novas atividades e Estudos de Impactos de Inovações, à aprovação do Conselho Distrital.

O desafio é a elaboração de normas que regulamentem a preservação do patrimônio e da paisagem, na forma de legislação municipal específica, integrada ao Plano Diretor em revisão, contemplando a delimitação de zonas de preservação mais abrangentes e estratégicas, solucionando as interfaces entre o urbano e o rural e definindo diretrizes mais específicas para as edificações inventariadas.

\section{Conclusão}

A ampliação do conceito de patrimônio cultural trouxe consigo a necessidade contínua de evolução dos instrumentos de preservação e gestão patrimonial. A compreensão da cidade como um conjunto de camadas que ao longo do tempo vão se substituindo, demanda a reflexão, pela sociedade, de quais expressões de sua história se desejam preservar. A preservação do patrimônio cultural de um povo de forma sustentável implica em um enfoque culturalmente diversificado e na participação direta da população envolvida, sob pena de ser preservado apenas um cenário. Ao mesmo tempo, a noção de desenvolvimento sustentável sugere que esse patrimônio deve ser acessível às gerações futuras, tanto como recurso econômico, tanto como valor social.

A atividade turística tem sido amplamente utilizada como estratégia de valorização, reabilitação e sustentação econômica de bens culturais materiais e imateriais. Ao mesmo tempo, a valorização de atividades produtivas através de indicações geográficas tem grande contribuição na melhoria da qualidade dos produtos, na preservação do meio ambiente e das paisagens e até mesmo na valorização de um patrimônio nem sempre reconhecido. Em ambas as situações, a valorização econômica e social trouxe um novo ânimo e principalmente qualidade de vida à população envolvida. Por outro lado, a transição para turismo de massa pode provocar a descaracterização da paisagem e o processo de gentrificação, causando o efeito contrário.

A escolha do que preservar e de como um território deve se desenvolver depende de um planejamento com visão macro e de longo prazo, que deve ser feito de forma contínua e participativa. A preservação do patrimônio cultural em sua forma mais ampla -a Paisagem Cultural - sob a instituição do instrumento da Chancela ou apenas através do reconhecimento local, depende de um acordo entre a sociedade, um pacto de gestão para o território.

O principal instrumento de planejamento urbano na escala municipal é o Plano Diretor Participativo, que pode ser a solução urbanística para a integração entre os instrumentos de gestão preservacionista e os de planejamento urbano. Com instrumentos de gestão da paisagem, construído em conjunto com a comunidade, definindo áreas de conservação e 
diretrizes especiais de acordo com as peculiaridades de cada local, tendo sua gestão através de conselhos municipais temáticos e revisado a cada dez anos, o próprio Plano Diretor pode ser entendido como um pacto de gestão da paisagem cultural.

Para a efetividade da Chancela e sustentabilidade do instrumento, no entanto, o pacto de gestão deve ser ampliado para todo o território envolvido, ou seja, ser feito de forma regional, integrando o planejamento com os municípios vizinhos, aliado ao incentivo à pesquisa, bem como participação do poder público e da população como um todo.

\section{Agradecimentos}

À orientadora e à equipe de professores e monitores do Curso de Especialização em Reabilitação Ambiental Sustentável Arquitetônica e Urbanística. Aos colegas do Instituto de Pesquisa e Planejamento Urbano, do Conselho Municipal de Patrimônio Histórico e Cultural e da Prefeitura Municipal de Bento Gonçalves.

\section{Referências}

APROVALE. Manual de indicação geográfica do Vale dos Vinhedos. Bento Gonçalves: APROVALE, 2012.

ARAÚJO, Guilherme Maciel. Instrumentos urbanísticos na preservação do patrimônio - áreas de conservação e planos urbanos. In: ARAÚJO, Guilherme Maciel. ASKAR, Jorge Abdo. MIRANDA, Marcos Paulo de Souza (organizadores). Mestres e Conselheiros: Manual de atuação dos agentes do Patrimônio Cultural. Belo Horizonte: IEDS, 2009.

BENTO GONÇALVES (2006). Lei Complementar $\mathrm{n}^{\circ} 103$, de 26 de outubro de 2006. Dispõe sobre o desenvolvimento urbano e rural do Município de Bento Gonçalves, institui o novo Plano Diretor de desenvolvimento Integrado do Município de Bento Gonçalves e dá outras providências. Versão compilada. Bento Gonçalves: IPURB, 2011.

BERTOCO, Cristiane. (2008) Roteiros Turísticos no Contexto da Aglomeração Urbana do Nordeste/ RS. Monografia apresentada para aprovação na disciplina de Laboratório de Arquitetura e Urbanismo. Caxias do Sul: UCS, 2008.
BERTOCO, Cristiane. (2014) Sustentabilidade, planejamento urbano e instrumentos de gestão do patrimônio e da paisagem cultural em Bento Gonçalves/RS. Monografia (Curso de pósgraduação latu sensu em Reabilitação Sustentável Arquitetônica e Urbanística). Programa de Pesquisa em Pós-graduação. Faculdade de Arquitetura e Urbanismo. Brasília: Universidade de Brasília, 2014.

BRASIL (2002). Estatuto da cidade: guia para implementação pelos municípios e cidadãos: Lei n. 10.257, de 10 de julho de 2001, que estabelece diretrizes gerais da política urbana. - 2. ed. Brasília: Câmara dos Deputados, Coordenação de Publicações, 2002.

BRASIL (2004). MINISTÉRIO DAS CIDADES. Plano diretor participativo: guia para elaboração pelos municípios e cidadãos. Brasília. Ministério das Cidades, Confea, 2004.

CONSELHO DA EUROPA (1975). MANIFESTO DE AMSTERDÃ: carta européia do patrimônio arquitetônico ano do patrimônio europeu. Disponível em: <http://portal.iphan.gov.br/portal/ baixaFcdAnexo.do?id=266> Acesso em: 06 jul 2014.

CONSELHO DA EUROPA (1995). Recomendação Europa sobre a conservação integrada das áreas de paisagens culturais como integrante das políticas paisagísticas. <http://portal.iphan.gov.br/portal/ baixaFcdAnexo.do?id=266> Acesso em: $10 \mathrm{mar}$ 2014.

CUÉLLAR, Javier Pérez. (Org). Nuestra Diversidad Creativa - Informe de la Comissión Mundial de Cultura y Desarrollo: Versión resumida. Paris: UNESCO, 1996.

DELPHIM, Carlos Fernando de Moura. Análise da paisagem cultural da região de Bento Gonçalves RS. Brasília: Coordenação de Patrimônio Natural do Departamento de Patrimônio Material e Fiscalização, IPHAN, 2013.

DE PARIS, Assunta (coord.) Memórias Bento Gonçalves - RS: fundamentação histórica. Bento Gonçalves: Prefeitura Municipal de Bento Gonçalves; Arquivo Histórico Municipal, 2006.

IPHAN, Instituto do Patrimônio Histórico e Artístico Nacional (2011). Reflexões sobre a chancela da Paisagem Cultural Brasileira. Brasília: IPHAN; Coordenação da Paisagem Cultural, março de 2011. 
FALCADE, Ivanira (Org.); MANDELLI, Francisco (Org.). Vale dos vinhedos: caracterização geográfica da região. Caxias do Sul: EDUCS, 1999.

FLORES, Maria Amélia Duarte. FLORES, Andiara. Diagnóstico do enoturismo brasileiro: um mercado de oportunidades. Brasília, DF: SEBRAE ; Bento Gonçalves, RS : IBRAVIN, 2012.

GOMES, Gisella. Planejar - Preservar Desenvolver: a cidade de Sobral. Dissertação de Mestrado. Brasília: Faculdade de Arquitetura, Universidade de Brasília: 2011.

MEDEIROS, Ana Elisabete de Almeida. Materialidade e Imaterialidade Criadoras: o Global, o Nacional e o Local na Construção Social do Patrimônio Cultural - O Bairro o Recife como Caso. Tese de Doutorado. Brasília: Departamento de Sociologia, Universidade de Brasília, 2002.

O Bairro o Recife como Caso. Tese de Doutorado. Brasília: Departamento de Sociologia, Universidade de Brasília, 2002.

OLTRAMARI, Fernando. BORGUETTI, Luiz Marcos. Projeto cultural Caminhos De Pedra: fase 2. Bento Gonçalves: Associação Caminhos de Pedra, 2005.

OEA: Organização Dos Estados Americanos. Normas de Quito (1967). Disponível em: < http://portal.iphan.gov.br/portal/baixaFcdAnexo. do?id=238> Acesso em: 11 mai 2013.

POSENATO, Júlio. "Caminhos de Pedra" - Linha Palmeiro - Distrito São Pedro - Bento Gonçalves: Projeto de Resgate da Herança Cultural . 1998. 